\title{
Analysis on Promoting Employment of College Graduates Under the COVID-19 Pandemic
}

\author{
Jiarui $\mathrm{Li}^{1, *}{ }^{*}$, Xixi $\operatorname{Lin}^{2, \dagger}$, Ziyu $\operatorname{Liu}^{3, \dagger}$ \\ ${ }^{1}$ International Business School, Chongqing Technology and Business University, Chongqing, China \\ ${ }^{2}$ Business School, Renmin University of China, Beijing, China \\ ${ }^{3}$ School of Finance and Taxation, Zhongnan University of Economics and Law, Wuhan, China \\ *Corresponding author email: 20143095@stu.nun.edu.cn \\ These authors contributed equally
}

\begin{abstract}
Full employment of college graduates is an ideal condition for a country's stability and progress. The impact of COVID-19 in 2021 has put forward new requirements for stabilizing the employment of college graduates in China. Under such circumstances, this paper investigates the current status and the issues of employment of college graduates. Specifically, it discusses the mismatch between professional skills and the job available for the fresh graduates, the rat race of employment between first-tier cities and new first-tier but the lack of employment attraction of second-tier cities and third-tier cities, as well as the lack of entrepreneurship of college graduates. In addition, the changes of pattern of graduate student employment are also analyzed. Such as the popularity of the internet+ model and the increasing number of flexible workers. These paper also focuses on the changes of employment expectation and destination. To alleviate the employment problems of college graduates under the normal epidemic prevention and control, this paper puts forward suggestions from the perspective of universities society and government. These results shed light on finding and solving the employment issues the college graduates are facing with in 2021.
\end{abstract}

Keywords: COVID-19, college graduates, pattern of employment, employment policy.

\section{INTRODUCTION}

\subsection{Research background and significance}

The outbreak of COVID-19 in early 2020 has greatly affected the orderly development of global economy, with plenty of impacts on different groups in various industries and fields. By the beginning of 2021, China had initially overcome the COVID-19 epidemic and entered the stage of regular epidemic prevention and control. However, the trend of the epidemic abroad and the gradual arrival of the "post-epidemic era" at home have posed new challenges to the country's development and employment of people's livelihood. At present, the way to promote employment has become a hot topic.

Employment is fundamental to people's wellbeing and the foundation for social stability. The full employment of college graduates is a necessary condition for the stability and progress of a country. Since the outbreak of the epidemic, the CPC Central
Committee and The State Council have attached great importance to the employment of college graduates. General Secretary Jinping Xi has issued a series of important instructions, requiring multiple measures to improve the employment of college graduates and other groups. Premier Keqiang Li also made several special plans. The State Council has put stabilizing employment at the top of its six measures to stabilize social development in response to the epidemic. "The total number of regular college graduates in 2021 will be 9.09 million, 350,000 more than last year." Wang Hui, director of the Department of College students under the Ministry of Education, admitted at a press conference that the epidemic is still having a profound impact on employment, and the employment situation for college graduates in 2021 is still complex and grim. "The increasing number of unemployed college students and overseas returnees last year, coupled with the large number of graduates this year, has increased the pressure on college students to find jobs," said Li Qiang, executive vice-president of Zhaopin.com. It can be seen that although China has entered the stage of normal 
epidemic prevention and control, the employment problem faced by college students is still severe. Therefore, it is still necessary to study the employment problem of college students.

\subsection{Literature Review}

COVID-19 has had a significant impact on the employment of college graduates. Shen Guobing (2020) made a root cause analysis from the perspective of foreign trade. He believed that COVID-19 had a great impact on China's trade, blocked China's economic export and aggravated the employment problem of college graduates [1]. Yue Changjun (2020) investigated from the perspective of the employment market. He stated that the occurrence of COVID-19 has reduced the demand of the labor market, but the scale of college graduates is increasing year by year, resulting in the imbalance between labor supply and demand. In addition, the difficulty of employment and self-employment in foreign countries has increased, intensifying the employment competition [2]. COVID-19 has also had a direct impact on college graduates. Zhong Yunhua and Wang Jiaohua (2020) found that the outbreak of COVID19 caused an increase in employment costs for college graduates, including time cost, economic cost and opportunity cost. In addition, college students have to prepare for job hunting in a short time and job hunting channels blocked all lead to great pressure to students, i.e., there is almost no positive situation. Furthermore, the outbreak of COVID-19 has caused a decline in employment quality, including the decline in salary and benefits, job satisfaction, human-job matching and working environment [3].

In order to stabilize the employment of college graduates, the state has also issued a number of policies to stabilize the employment of college graduates. From the macro level, Shen Guobing (2020) believes that the government should use fiscal and monetary policies to support stable enterprises and employment. The government can increase exports, imports and employment by directionally increasing market liquidity, reducing enterprise costs and expanding consumption, thus promoting China's economic growth and further alleviating employment pressure [1]. At the government level, Chen Jianwei and Lai Desheng (2020) divide employment promotion measures into "universal preferential policies" and "specialized policies". Inclusive policies mainly include reducing or exempting payments by employers, strengthening the development of the public service system for small and medium-sized enterprises, and stabilizing employment with all kinds of employment subsidies. Specialized policies include actively utilizing major projects to attract more college graduates for employment, arranging job vacancies in public institutions to guide more college students to work at the grass-roots level, actively exploiting the employment potential of state-owned enterprises, and expanding the employment scale of college students absorbed by enterprises [4].

Moreover, many scholars put forward many suggestions from the perspective of universities and graduates. Huang Suya and Gong Beijie (2020) pointed out that the scale of postgraduate students can be expanded, college students can be encouraged to start their own businesses, and big data can be used for manpost matching analysis [5]. Chen Jianbang (2020) proposed from the direction of employment guidance that colleges and universities should strengthen the guidance of employment concept, guide graduates to serve the needs of the country, and improve the construction of employment information system, etc., which serves as a good guiding role in the work of colleges and universities [6]. Zhang Hongqi and Zhao Yue (2020) suggested that college students ought to establish a good mentality, improve comprehensive competitiveness, and seize new employment opportunities and entrepreneurial opportunities [7].

\section{ANALYSIS OF EMPLOYMENT STATUS AND PROBLEMS OF COLLEGE GRADUATES}

\subsection{Selecting a Template Analysis of Employment Status of Fresh College Graduates under COVID-19}

In 2020, one of the serious impacts of COVID-19 on economic development is the reduction of jobs. However, the normalization of COVID-19 makes it difficult to change the situation of insufficient employment demand in a short period. The imbalance between supply and demand and the competition of employment have put college graduates under great pressure. In order to ease the employment pressure of fresh graduates, government issued relevant policies for students, enterprises, including expanding channels for further study, increasing employment guidance, adapting to the "slow employment" mode of fresh graduates, giving subsidies to enterprises for job expansion, and promoting fresh graduates to work at the grassroots level. Based on the experience in 2020, China will further strengthen the efforts to stabilize the employment of college graduates in 2021 and a new situation has emerged in the employment of college graduates. There are three main changes: the change of employment mode, expectation and orientation. Meanwhile, the number of college graduates in 2021 in China has reached a record high of 9.09 million, the pressure and difficulties of employment is necessary to concern. The employment mode and the employment concept of college students or values are inseparable. Since the outbreak of COVID-19, on the one hand, due to the 
significant increase in the uncertainty of economic development expectations, college students have increased the attitude of seeking stability in employment. Working for government and state-owned company have become important considerations for college students when choose jobs. On the other hand, due to the requirements of isolation and social distance, college students have more acceptance of free, independent and separate employment. In terms of the ways to obtain employment, online began to occupy an important weight than offline. All on-site recruitment activities have been suspended and replaced by online recruitment. This change in recruitment mode is a new challenge not only for recruitment enterprises, but also for fresh graduates.

\subsection{Employment problems brought by COVID- 19 to college graduates}

\subsubsection{Mismatch problem between professional skills and job demands}

This problem is mainly reflected in the mismatch of major and the insufficiently close connection between the knowledge learned in school and the job requirements of enterprises. On the one hand, employers' requirements for graduates do not match their reserves of professional knowledge. On the other hand, there is a certain gap between the content of on-campus learning of some majors and the content of workplace requirements.

\subsubsection{The rat race of employment and the lack of employment attraction}

According to the report on employment trend of 2021 fresh students directly employed by boss as illustrate in Fig. 1, students in the first-tier and new first-tier cities have strong aspirations to get a job in the cities where they attend in college. Only $12.4 \%$ of students study in the first-tier cities but the cities have the strongest attraction of employment. First-tier cities are also the first choice for many students studying in other cities except local students. College graduates have more likely to choose first-tier cities than new first tier cities. Recently, the development of new first-tier cities has alleviated the stress of employment of first-tier cities effectively. The high portion of students studying in new first-tier cities is reaching $31.2 \%$. The new first-tier cities also have the strongest employment absorption capacities and it is about $37.1 \%$. However, from the 2020 CIER index provided by Zhaopin.com, one can see the CIER index is 0.68 for the first-tier cities and 0.92 for the new first-tier cities. That means there are great competition in these two kinds of cities especially for the first-tier cities.

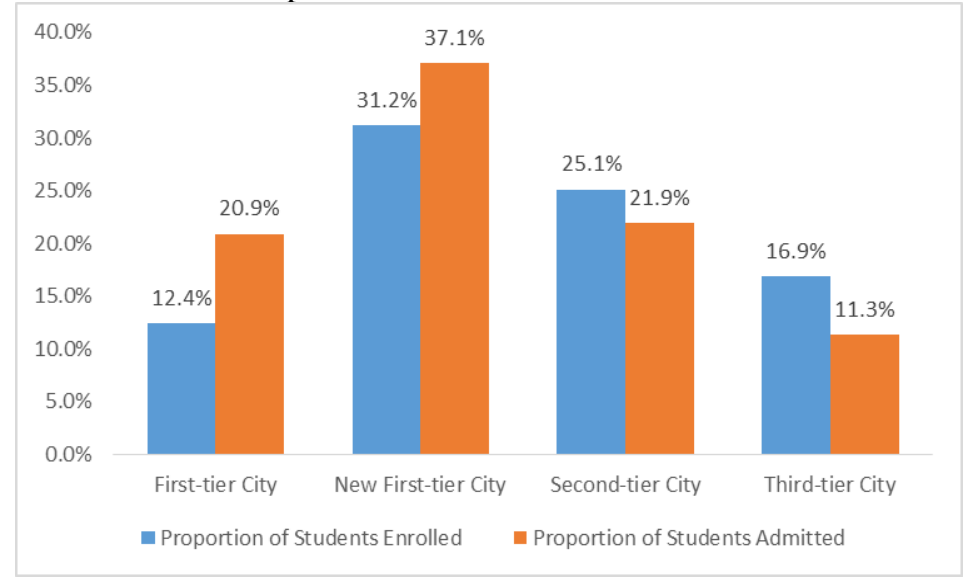

Figure 12021 Regional Distribution of Students Enrolled and Admitted

Data Resource:www.zhipin.com "Report on Employment Trends of Final Year Students 2021"

Look at the second-tier cities and the third, fourth and fifth tier cities, they have a high portion of students enrolled but the portion of attraction of employment is lower than the portion of students enrolled. Meanwhile, the highly educated talents have lower willingness to work in the second-tier and lower cities. In addition, the CIER index of the second-tier cities is 1.2 and of the third-tier cities is 1.83 . It shows that there is no tense competition in the job market. One the one hand, it may be owing to the lack of matching between jobs and highquality talents in second- and third-tier cities, which means it is hard for the high-quality talents choose to stay. On the other hand, it can be attributed to the incomplete change of students' employment concept, i.e., students still focus on the first-tier and new first-tier employment. Nevertheless, there is a huge competition on account of the requirement of employment. With the improving of public service level (e.g., education and life quality), many second-tier cities attract more graduates to settle down. The number of job seekers is increasing and the situation of employment is better than before, whereas it still has less attraction of employment. 


\subsubsection{The start-up environment is difficult}

The COVID-19 has had a huge impact on business operations. Companies have reduced the number of workers, or even laid off employees. Offline job recruitment fairs have been cancelled, and job opportunities have been greatly reduced. College graduates can't participate in the job recruitment fair, which isolating them at home. Lack of employment information caused panic as well. This situation seriously affects college graduates employment this year. The impact of the plague on college students' employment is mainly reflected in the reduction of employment opportunities and the cost increasing of employment and start business by them own. The difficulties and lower quality of employment and starting business has shown.

\section{CHANGES IN EMPLOYMENT PATTERNS OF COLLEGE GRADUATES UNDER THE EPIDEMIC}

\subsection{The "Internet plus" Employment Model has been Implemented}

At present, one of the main characteristics of the employment mode of college graduates is the gradual reduction of traditional offline recruitment fairs and the rise of the new employment mode based on "Internet +". The employment mode of "Internet +" has been gradually implemented and developed, and the employment mode has changed from single to diversified, combining offline and online. Thus, college graduates can achieve employment to the greatest extent, and reduce the impact of the epidemic on the employment of college graduates. During this period, "Cloud" information sessions, "Cloud" interviews, "cloud" internships etc. enable graduates to complete interviews without spending a lot of time traveling. This approach not only improves the efficiency of recruitment, but also solves cross-regional problems and boosts online recruitment reform [8].

\subsection{The Number of Flexible Workers Increased}

During the pandemic, new forms of employment have played an important role in stabilizing employment.
Major companies and enterprises promulgation various flexible employment policies, providing a better guarantee for the employment of graduates. There are six modes of flexible employment: labor dispatch, part-time, intern, part-time, rehired retirees and business outsourcing. For college graduates, interns and part-time jobs are the two main forms. Many companies have established school-enterprise partnerships with local universities. This mode not only alleviates the problem of labor shortage in enterprises, but also enables graduates to adapt to working life in advance by this way, clarify their employment direction, and reduce the employment confusion and anxiety caused by the epidemic. At the same time, online part-time jobs also provide employment channels for fresh graduates. For some simple tasks, e.g., checking water meters and answering complaints. Thereby, students can contact the student affairs Office and youth League committee of colleges and universities to organize students to work in the company. Part-time jobs not only reduce the recruitment pressure of enterprises during the epidemic, but also provide fresh graduates with a channel to contact the society and learn about employment [9].

\subsection{Changes of College Graduates' Employment Expectations}

As illustrated in Fig. 2, the "No Effect" is the largest proportion of the employment expectation of college graduates in 2021. The next is "Pay Down" and "Change of Industry". The "Change of Industry" is the highest proportion in 2020. The next is "Change of Workplace" and "Change of Jobs". The COVID-19 had almost no impacts on many students' employment expectations based on the national regulation of stable employment in 2020 and the experience of college students seeking jobs. "Pay Down" is relatively high but "Change of Industry", "Change of Workplace", "Change of Jobs" are not in a high portion in the survey of 2021. It shows that China's policies in stabilizing employment have played a better role in alleviate the problems of industry, workplace and jobs changes. However, in order to guarantee the salary level of senior employees and create more jobs under the epidemic situation, the COVID-19 has an impact on the real salaries of new graduates. 


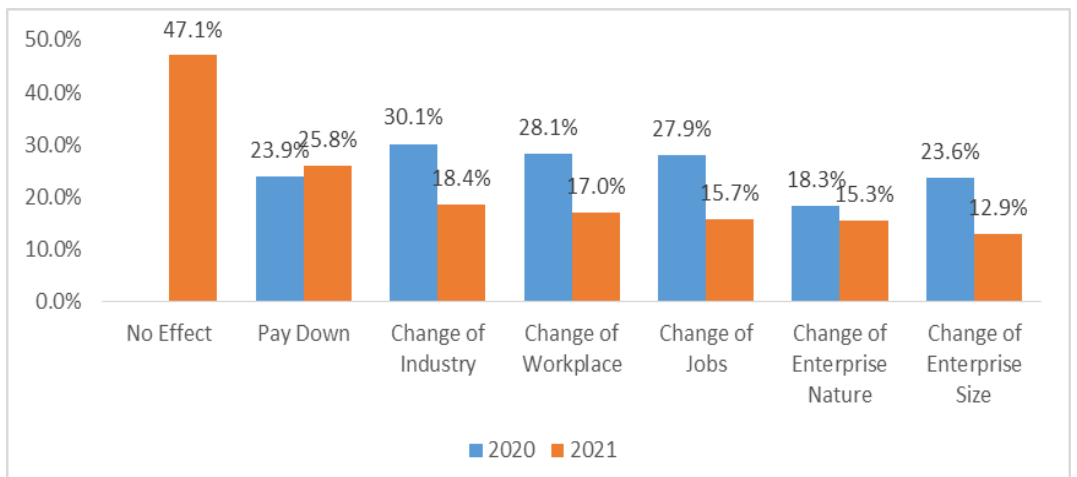

Figure 2 The Impact On The College graduates' Employment Expectations of COVID-19

Data Resources: www.zhaopin.com “2020 College Students Employability Report” and "2021 College Students

Employability Research Report"

\subsection{Changes of College graduates in Employment Directions}

There are some changes in the employment directions of college graduates through comparing the results in 2020 and 2021 in Fig.3. There are less students choose to select agencies for employment but more and more students choose to free work, delayed employment and future study in China. The number of students going abroad for further study has increased facing with the pressure of employment. Nevertheless, the increase rate is not large due to the impact of the global epidemic situation. China always encourages students to start a business and has great support for entrepreneurship to alleviate the pressure of employment. Whereas, the increase rate of students choose this way is not huge since the COVID-19 has some adverse effects that cause the industrial structure has changed and hard for the small and micro enterprises to get started.

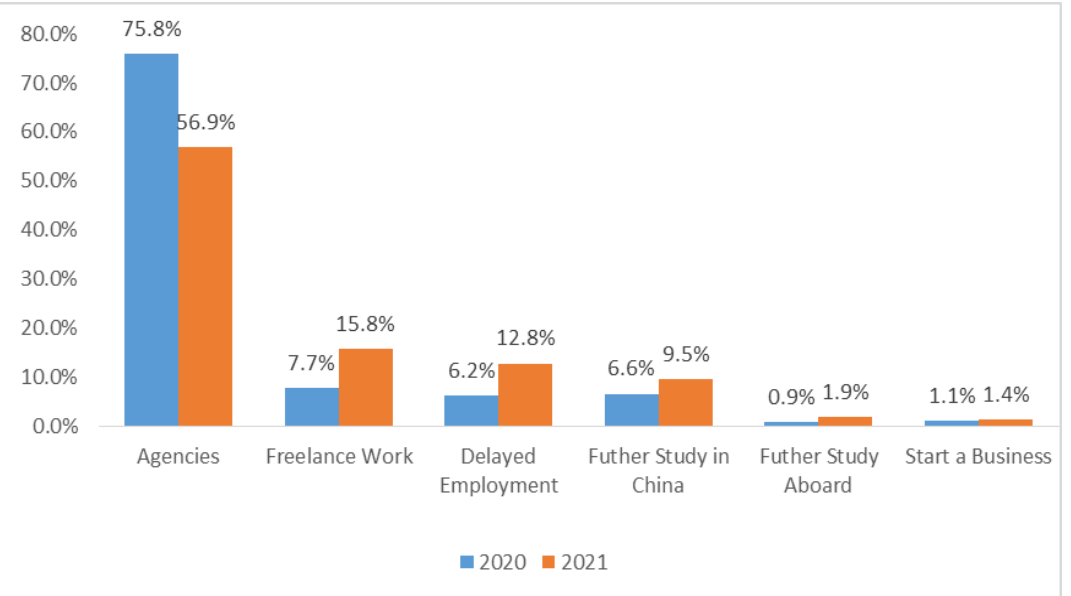

Figure 3 Changes of College graduates in Employment Directions

Data Resources: www.zhaopin.com "2020 College Students Employability Report” and "2021 College Students Employability Research Report"

\section{COLLEGE GRADUATES EMPLOYMENT COUNTERMEASURES}

\subsection{Universities Can Promote the Reform of Talent Training Programs to Meet the Job Needs of Employers}

On the one hand, universities should pay attention to the cultivation of compound talents, establish relevant platforms to promote students' practice and practice, and hold various activities to exercise students' abilities in various aspects. On the other hand, universities should set up the curriculum system scientifically under the premise of fully investigating the market demand, adjusting it timely according to the change of market demand. Major should be more detailed, fully corresponding to the needs, to achieve the goal of learning for use. Moreover, universities should update their majors and courses according to the social requirements, and constantly cater to the new market demand. The talent training program in universities should reflect the characteristics of the Times and meet the needs of The Times. In the meantime, fully rely on cloud technology to enrich the form of work. 


\subsection{Improve the Public Services in Second-and Third-tier Cities}

When the college graduates choose the cities to settle down, they may consider about the public services including education resources, medical and health level and the cover of public goods. Firstly, the second- and third-tier cities should try their best to improve the level of public services and get closer to the first-tier cities and to maintain the same level of life quality of college graduates. Secondly, these cities should make more policies which are suitable for college students to settle down, e.g., give graduates a substantial settlement costs, talent welfare, preferential education for children and pension benefits etc. to attract qualified personnel. Aside from the policy guarantee, the second- and third-tier cities should focus on the matching problems of jobs and students' profession. These cities should look for what the cities need and provide more jobs for graduates to choose. In addition, colleges should do a good job in guiding the employment of college students and guide more students to the second- and third-tier cities, to the grass-roots units to contribute to the construction of the motherland and promote the development of the region.

\subsection{Strengthen the Government's Precise Assistance to Employment}

The government has provided a broad employment information for college students by propaganda of employment policies and releasing employment information through offline brochures, banners and online public accounts. Build and improve the platform for business start-up, increase financial support and implement one-time subsidies, social security subsidies and guaranteed loans for college graduates. Setting up business start-up incubation system. Providing employment probation and other policies for those who want to doing business by themselves. We will strengthen oversight of the job market and protect the rights and interests of graduates in finding jobs or starting their own businesses. To create a good employment and start-up environment and protecting the employment and start-up market of fresh college graduates, should establish a dynamic feedback system and strengthen analysis and prediction for demands.

\section{DISCUSSION}

This paper focuses on the employment problems faced by college graduates in China from the outbreak of COVID-19 in late 2019 to July 2021. Subjective factors and objective epidemic situation aggravate the difficulty of employment. Some subjective reasons are lack of practical experience, lack of knowledge reserve and limitation of specialty. In addition, the impact of the epidemic is also severe, mainly reflected in two aspects: restricted internship and risk of going out[8]. Based on the experience of stable employment in China in 2020, the employment situation of college graduates in China in 2021 is still severe but somewhat eased. We find the problems and provide some suggestions through analyze the situation and the problems of employment, and the changes of pattern of employment from 2020 to 2021. Differently, previous studies mainly based on the situation during the initial outbreak of the COVID-19 and the epidemic prevention and control in 2020. They put forward many suggestions to solve the employment problems at that time. However, the new graduates in 2021 are facing a different employment situation that the pattern of employment changed under the impact of COVID-19 including the changes of jobs, expectations, directions. This paper offers more relative suggestions based on the new employment situation of 2021.

\section{CONCLUSION}

Since the prevention and control of the epidemic, the employment problem of college graduates in China is still serious, and new issues gradually appear in our vision. This paper uses the latest reports, real-time data based on reference to relevant literature to further investigate the employment of college graduates under the epidemic situation. According to the analysis of the current employment pattern changes, the current situation of college graduates. Hence, we concluded that the new employment problems faced by college graduates in 2021. These problems are mainly reflected in the mismatch between the professional skills of fresh graduates and the job demand, the fierce competition between first-tier and new first-tier jobs, the lack of attractiveness of second and third-tier cities, and the difficult market environment for fresh graduates to start their own businesses. To address the above problems, this paper analyzes the measures and puts forward innovative suggestions for the above three problems. The research results of this paper are conducive to providing guidance to college graduates to a certain extent and putting forward new solutions to employment problems in the normal epidemic prevention and control stage. However, due to the lack of partial data and relatively new topic, the problems found in this paper are not comprehensive enough and need further study by more scholars.

\section{REFERENCES}

[1] Shen Guobing.(2020). Impact of COVID-19 on China's foreign trade and employment and rescue measures. Journal of Shanghai University of International Business and Economics (2). 
[2] Yue Changjun.(2020). The impact of epidemic on employment of college graduates. Employment of College students in China (6)

[3] Zhong Yunhua, WANG Jiaohua. Negative impact of epidemic on employment of college graduates and countermeasures and suggestions. Employment of College Students in China (8),5.

[4] Chen Jianwei, Lai Desheng.(2020). Changes and countermeasures of college students' employment situation under the impact of epidemic. Employment of College Students in China (11).

[5] Huang Suya, Gong Beijie.(2020). Analysis on employment policies of fresh Graduates in the context of COVID-19. Modern Commerce \& Industry,000(017),209-211.
[6] Chen Jianbang.(2020). Thoughts on college students' employment guidance under the situation of fighting against epidemic. Employment of College students in China (6).

[7] Zhang Hongqi, Zhao Yuee.(2020). How college students respond to COVID-19 challenges to employment. Employment of College Students in China,000(005),38-43.

[8] Li Tao, Sun Pei, Wu Zhihui, \& Shan Na. (2020). An empirical study on employment status of College graduates in China under the impact of COVID-19. Journal of East China Normal University (Education Science) (10). 